\title{
The Dynamic of Synchronous Generator under Unbalanced Steady State Operation: A Case of Virtual Generator Laboratory
}

\author{
Sugiarto Kadiman, Arif Basuki, Mytha Arena \\ Department of Electrical Engineering, Sekolah Tinggi Teknologi Nasional, Yogyakarta
}

\begin{abstract}
Article Info
Article history:

Received Jun 29, 2015

Revised Aug 22, 2015

Accepted Sep 4, 2015

\section{Keyword:}

$500 \mathrm{KV}$ EHV

Jamali System

qd0 reference frame

Synchronous generator

Tecquiment NE9070 simulator

Unbalanced steady state

ABSTRACT

The purpose of this study is to design and develop a synchronous generator virtual laboratory for undergraduate student courses, which can be treated as an accessorial tool for enhancing instruction. Firstly, the study reviews the general concept and algorithm of synchronous generator model. Secondly, the simulation method of this system is discussed. Finally, the paper introduces its example and analysis. One of the major objectives of this project is the dynamics of synchronous generators connected to the $500 \mathrm{kV}$ EHV Jamali (Jawa-Madura-Bali) System under unbalanced steady state condition that could be modeled as a balanced synchronous generator's model with unbalanced voltage inputs. The balanced synchronous generator model based on the rotor's qd0 reference frame was chosen to substitute generator's model embeded in loadflow analysis. The verification of the proposed generator's model was checked by comparing it with a PSS Tecquiment NE9070 simulator. The unbalanced voltage inputs of generator were derived utilizing the loadflow analysis by determining the phase and sequence currents, and average bus voltages of the $500 \mathrm{kV}$ EHV Jamali grid considering unbalanced portion variations. Meanwhile, the load locations having significant effect on the test generators are obtained by using the electricity tracing method. The developed virtual laboratory with a given example demonstrated the usefulness of the tool for studying synchronous generator under unbalanced steady-state operation.
\end{abstract}

Copyright (C) 2015 Institute of Advanced Engineering and Science. All rights reserved.

\section{Corresponding Author:}

Sugiarto Kadiman,

Department of Electrical Engineering,

Sekolah Tinggi Teknologi Nasional,

Jl. Babarsari, Catur Tunggal, Depok, Sleman, Yogyakarta 55281, Indonesia.

Email: sugiarto.kadiman@sttnas.ac.id

\section{INTRODUCTION}

In electrical engineering education, written exercises are necessary for undergraduate students to grasp conception while experimentations emphasize the understanding of the subject. Real experiments are essential for developing skills to deal with instrumentation and physical processes and no doubt that nothing will replace synchronous learning through face to face interaction [1]. Virtual Laboratory can be treated as an accessorial tool of real laboratory to enhance instruction for conventional on-campus students, which can enable students to improve the skills before going to the actual laboratory, to learn breaking the limitation of real laboratory dealing with advanced topics, such as unbalanced operation in synchronous generators. So, Virtual Laboratory can effectively help to overcome the barriers imposed by the traditional education by using an innovative combination of a new approach to education and the application of new technologies [2][4]. 
Many studies considering unbalanced steady state operating conditions of synchronous generators as a source electrical energy have done using the analytical approaches. The nature of the unbalance comprises unequal voltage magnitudes at the fundamental of both system frequency and phase angle deviation. One of contributing factors is the appearance of unbalanced loads of the generator. In crucial unbalanced systems, negative sequence current may cause overheating of the machineries; zero sequence current may cause improper action of the protective relaying [5].

Unbalanced short-circuits calculating of synchronous generator under steady state operation has been completely understood [6]-[7]. Analysis based on mathematical theory which includes single line-toneutral fault and the line-to-line fault, is been utilized. But another problem of the unbalance when the system is connected the grids has not been thoroughly solved [8].

Until now there is no theoretic mathematics models of synchronous generators used to analyze this kind of problems mentioned above. If there is a study that addresses the issue, it requires an exhausted equation, such as Salim who analyzed the small signal dynamic performance of synchronous generator connected to the load under any unbalanced operation conditions. Such model uses differential algebraic equations (DAE) which is composed by differential equations of generators (electrical and mechanical parts) and its controls (voltage and speed regulation), and by algebraic equations from generator, its control, and the network. The examined system is Single Machine Infinite Bus or SMIB. The results are frekuensi (f) and damping ration $(\xi)$ of the electromechanical model calculated in each studied case of unbalanced scenario [910]. Another researchers, such as Ramya and Selvi are also focused on SMIB. Synchronous generator model uses Heffron-Phillips Model with/without amortiseur winding. Analysis focuses on small signal stability, such as the incoming of changing voltage reference and step change in the mechanical torque $\left(T_{m}\right)$. The results present response curves of terminal voltage, field voltage, rotor speed, and angle [11]. Another researchers had focused on the isolated self-excited induction generator (SEIG) balanced/unbalanced conditions of loads [12-14].

Acha [15] suggests that loadflow analysis can be used to analyze unbalanced steady-state problems of synchronous generator as long as more realistic synchronous generator model is implemented. So the goal of this paper is to obtain a comprehensive mathematical model of balanced synchronous generator operated under unbalanced steady state condition. It is indispensable synchronous generator model which has a completely enough framework for analyzing the small-signal dynamic performance of power systems under unbalanced conditions and also can accommodate the loadflow analysis to determine values of generator's terminal inputs when the changing loads happened on the connecting grids.

The presented study considers several typical synchronous generators which are connected to 500 kV EHV Jamali System, Indonesia. The study was carried out through the "hybrid" method by combination both unbalanced loadflow under EDSA 2000 to analyze the grid and to determine the inputs of the test generator and the rotor's qd0 reference frame of synchronous generator model to substitute the loadflow generator's model [16-17]. The verification of the proposed model was checked by comparing it with a Tecquiment NE9070 simulator. The developed model is a main subsystem of synchronous generator virtual laboratory.

This work is organized as follows. A brief explanation about the concepts and algorithms involving the unbalanced condition of balanced synchronous generator is defined on Section 1. Section 2 presents the review concepts and algorithm. The simulation methods are presented on Section 3. Section 4 presents the results and conclusion.

\section{REVIEW CONCEPTS AND ALGORITHMS}

A brief discussion considering the operation of power system with synchronous generators under steady state unbalanced conditions is presented in the present section.

\subsection{Steady State Unbalanced Operation}

Many large synchronous generators connected to the power grid are usually found in recent power system, which is common in several countries around the world, including Indonesia. The $500 \mathrm{kV}$ EHV Jamali Systems is one of an example. Synchronous generators often operates on unbalanced three-phase loading. That is the stator currents have different amplitudes, and their phase displacement differs from $120^{\circ}$ [18]. These phase currents can be decomposed in positive, negative and zero sequence currents according to Fortesque's transform. At rotor speed, the positive sequence components produce a forward-traveling magneto motive force and are only appeared in balanced operation of the synchronous generator.

At unbalnced operation, armature current presents negative and zero sequence components the negative sequence components. Negative sequence produces MMF that travels at opposite rotor speed, the zero sequence components produce a zero traveling field in an air-gap and do not interact with the rotor in 
term of the fundamental component. Both, positive and negative sequence components under unbalanced steady state condition produce a net magneto-motive force with a sinusoidal variation of its maximum amplitude and will also appear a sinusoidal variation with a frequency. Consequently, the speed of the generator will not be constant in steady state condition.

\subsection{Synchronous Generator Dynamic Mathematical Model}

For all of usual generator application, there is more than one generator operating in parallel to supply demanded by the loads. To analyze the dynamic of generators under unbalanced steady state operation, which is power angle or load angle characteristic, a "hybrid" method by combination between unbalanced three phase load flow analysis and rotor's qd0 reference frame of generator model which substitutes the model of generator in load flow analysis can be used.

The dynamic mathematical model of a balanced synchronous generator with one q-axis damping winding is composed by the set of differential equations as resented in Figure 1 and also below [19].

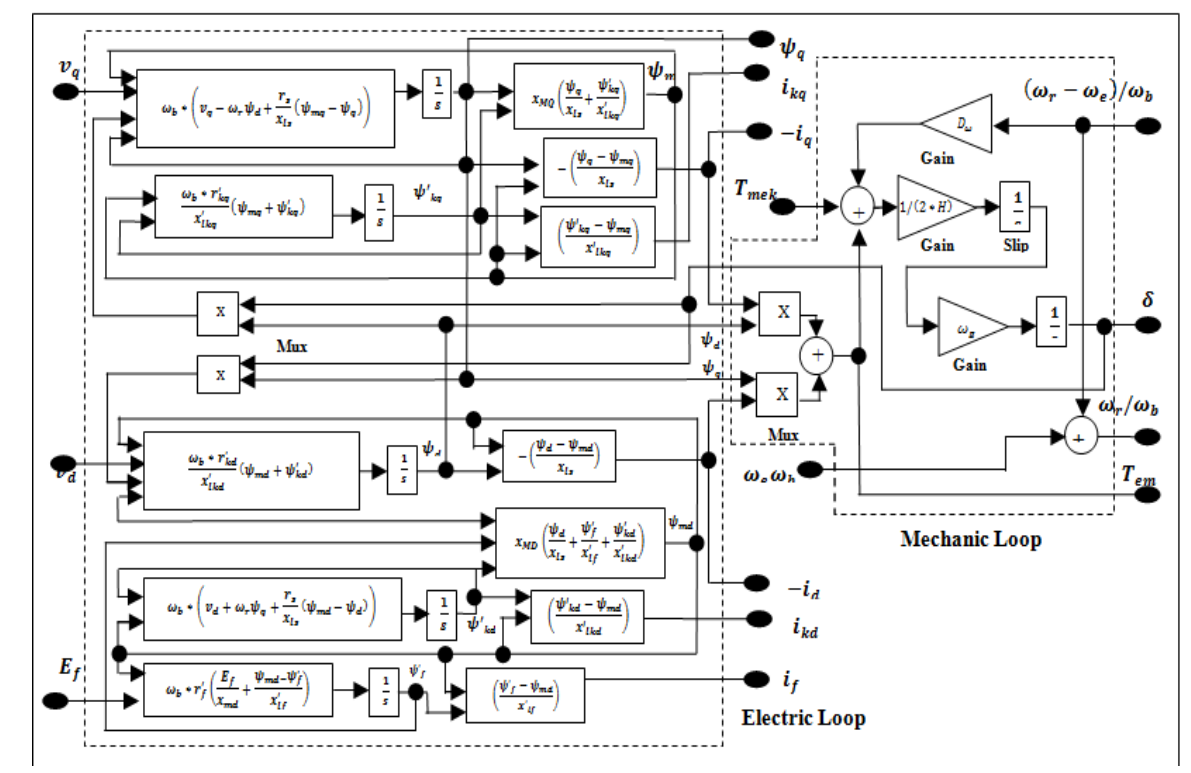

Figure 1. Inner block of balanced three-phase synchronous generator [17]

The differential equations of electrical dynamic that describe the stator and rotor windings and are written in qd0 reference frame are, shown in (1).

$$
\begin{array}{ll}
v_{q s}^{r}=-r_{s} i_{q s}^{r}+\frac{\omega_{r}}{\omega_{b}} \psi_{d s}^{r}+\frac{p}{\omega_{b}} \psi_{q s}^{r} & v_{d s}^{r}=-r_{s} i_{d s}^{r}+\frac{\omega_{r}}{\omega_{b}} \psi_{q s}^{r}+\frac{P}{\omega_{b}} \psi_{d s}^{r} \\
v_{0 s}^{r}=-r_{s} i_{0 s}^{r}+\frac{p}{\omega_{b}} \psi_{0 s}^{r} & v_{k q}^{r}=-r_{k q} i_{k q}^{r}+\frac{p}{\omega_{b}} \psi_{k q}^{r} \\
v_{k d}^{r}=-r_{k d} i_{k d}^{r}+\frac{p}{\omega_{b}} \psi_{k d}^{r} & v_{f d}^{r}=-r_{f d} i_{f d}^{r}+\frac{p}{\omega_{b}} \psi_{f d}^{r}
\end{array}
$$

The first three equations describe the stator winding (subscript $s$ ) and the following three equations describe the rotor winding (superscript $r$ ). The subscript $k$ is used for the damping windings ( $k q$ for $q$-axis damping winding and $k d$ for direct axis) while the subscript $\mathrm{f}$ is used for the field winding.

In these $v$ represents the voltage of windings, $I$ describes the electrical current flowing in the winding, $\psi$ represents the magnetic flux connecting the winding, $p$ represents differential operator $(d / d t), \omega_{r}$ and $\omega_{b}$ are angular speed of the rotor refered to a two pole generator and reference angular speed corresponded to the rated frequency, respectively. The magnetic flux $\psi$ for each winding is represented in (2). Since the damping windings are short-circuited so the value of $v_{k q}^{r}$ and $v_{k d}^{r}$ are null.

$$
\begin{array}{ll}
\psi_{q s}^{r}=-x_{l s} i_{q s}^{r}+x_{m q}\left(-i_{q s}^{r}+i_{k q}^{r}\right) & \psi_{d s}^{r}=-x_{l s} i_{d s}^{r}+x_{m d}\left(-i_{d s}^{r}+i_{f d}^{r}+i_{k d}^{r}\right) \\
\psi_{0 s}^{r}=-x_{l s} i_{0 s} & \psi_{k s}^{r}=x_{l k q} i_{k q}^{r}+x_{m q}\left(-i_{q s}^{r}+i_{k q}^{r}\right)
\end{array}
$$




$$
\psi_{k d}^{r}=x_{l k d} i_{k d}^{r}+x_{m d}\left(-i_{d s}^{r}+i_{f d}^{r}+i_{k d}^{r}\right) \quad \psi_{f d}^{r}=x_{l f d} i_{f d}^{r}+x_{m d}\left(-i_{d s}^{r}+i_{f d}^{r}+i_{k d}^{r}\right)
$$

Where $r_{s}, r_{k q}, r_{k d}, r_{f d}, x_{l s}, x_{l k q}, x_{l k d}, x_{l f d}, x_{m q}$ and $x_{m d}$ are the electrical fundamental parameters of synchronous generator. The direct-axis reactance $x_{d}$ and the quadrature-axis reactance $x_{q}$ are given by (3).

$$
x_{d}=x_{l s}+x_{m d} \quad x_{q}=x_{l s}+x_{m q}
$$

The mechanical part of the generator is described by two differential equations as described in (4).

$$
p \delta=\omega_{r}-\omega_{s} \quad \frac{2 H}{\omega_{s}} p \omega_{r}=T_{m}-\left(\psi_{d} i_{q s}-\psi_{d} i_{q s}\right)-T_{d a m p}
$$

In Equation (4), $H$ is an inertia constant of the turbine-generator set, $T_{m}$ is the mechanical torque of the turbine and $T_{\text {damp }}$ is a damping torque. The damping torque represents the rotational losses of the rotating parts which consist of the magnetic losses and the mechanical losses.

\subsection{Balanced Synchronous Generator with Unbalanced Loads}

The balanced three-phase synchronous generator's model is shown in Figure 2. It is clear that the generator is driven by the unbalanced voltage inputs; thus:

$$
\left.\begin{array}{l}
V_{a g}=V_{m 1} \cos \left(\omega t-\gamma_{1}\right) \\
V_{b g}=V_{m 1} \cos \left(\omega t+\frac{2 \pi}{3}-\gamma_{2}\right) \\
V_{b g}=V_{m 1} \cos \left(\omega t+\frac{4 \pi}{3}-\gamma_{2}\right)
\end{array}\right\} \quad \gamma_{1} \neq \gamma_{2} \neq \gamma_{3}
$$

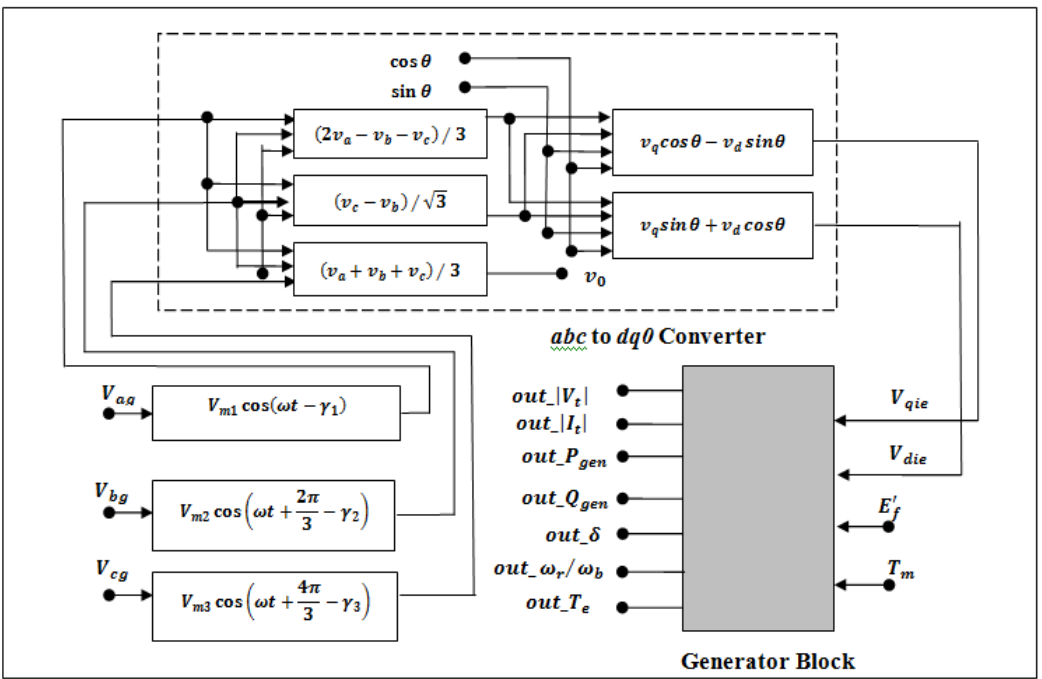

Figure 2. Balanced generator with unbalanced inputs, $\gamma_{1} \neq \gamma_{2} \neq \gamma_{3}$ [17]

\subsection{Electricity Tracing}

The tracing electricity is tracing the relationship between generator and loads using a load flow analysis. It could be difficult to realize because the changing on a demand of generator for every node will produce the changing stimulated on generation which produced by a swing-bus. One of the ideas of electricity tracing called the common method is sharing inflow of the nodes divided proportionally among the outflow of the nodes [20].

The common method will categorize buses and branches within the networks into several groups:

1) Domain of generators is defined as the set of buses which are reached by power produced by this generation.

2) Power from a generator reaches a particular bus if it is possible to find a path through the network from the generator to the bus for which the direction of travel is always consistent with the direction of the flow as computed by a power flow program. 
3) Commons is defined as a set of neighboring buses supplied by the same generators. Unconnected sets of buses supplied by the same generators are treated as separate commons. A bus therefore belongs to common. The rank of a common is the number of generators supplying power to the buses comprising this common.

4) Links is one or more external branches connecting the same common form.

5) State graph is the state of the system can be represented by a directed, acyclic graph; common are represented as nodes and links as branches.

The contribution to the load of a common is obtained by using the definition of the inflow and the outflow of commons. The inflow is the sum of the power injected by sources connected to buses located in this common and of the power imported in this common from other commons by links. And the outflow of commons is equal to the sum of the power exported through links from this common to commons of higher rank. The inflow of a common is equal to the sum of its outflow and of all the loads connected to the buses comprising the common.

The equations of contribution generator into load are:

$$
\begin{aligned}
& F_{i j k}=C_{i j} * F_{j k} \\
& I_{k}=\sum_{j} F_{j k} \\
& C_{i k}=\frac{\sum_{j} F_{i j k}}{I_{k}}
\end{aligned}
$$

Where $C_{i j}$ and $C_{i k}$ are contribution generator $i$ into loads and outflow of the common $j$ dan k, respectively. $F_{j k}$ and $F_{i j k}$ are the flows at the link between common- $j$ and $k$ and the flows at link between common $j$ and $k$, respectively.

\section{SIMULATION METHOD OF SYNCHRONOUS GENERATOR DYNAMIC}

To study the dynamic of synchronous generator from the small-signal point of view, several simulations were performed under EDSA 2000 and Matlab/Simulink. The process of numerical simulation method can be presented by the block diagram of Figure 3, in which the role and content of the box simply illustrated a follows:

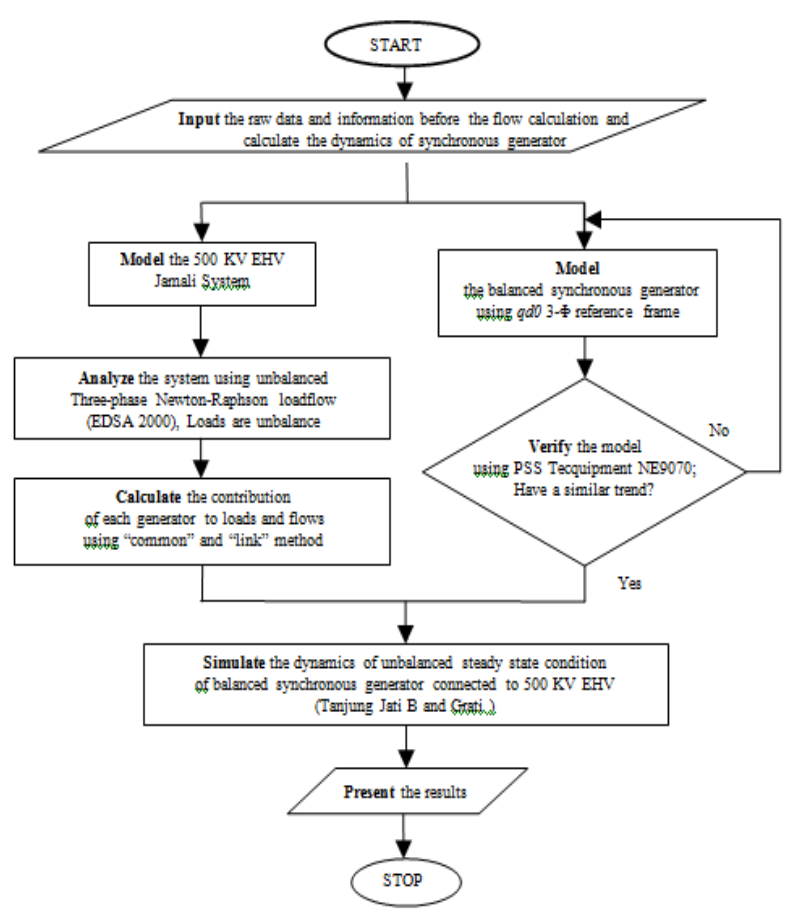

Figure 3. Simulation flowchart 
The unbalanced Three-phase Newton-Raphson Loadflow, EDSA 2000, is used to analyze unbalanced steady state condition of the $500 \mathrm{kV}$ EHV Jamali Systems. The substitution of the loadflow generator's model consisted of active and reactive power injections by the rotor's qd0 reference frame of synchronous generator model is intended to find the phenomenon influenced by unbalanced three-phase. To determine the verified model, the proposed generator model of balanced synchronous generator is compared with PSS Techquipment NE 9070 through similarity of their trends. The results of loadflow analysis are then used as the inputs of balanced synchronous generator's model which uses qd0 reference frame.

\section{RESULTS AND ANALYSIS}

\subsection{The $500 \mathrm{kV}$ EHV Jamali System}

The studied system is the $500 \mathrm{kV}$ EHV Jamali System that comprises 4-regions, such as Region I Banten-Jakarta, Region II West Java, Region III Central Java-Yogyakarta, and Region IV East Java-Bali. It also has 71 line nodes, 27 lines of inter buses, and 9 generator nodes ,such as Suralaya 2450 MW, Cirata 1400 MW, Muara Tawar 500 MW, Saguling 450 MW, Grati 750 MW, and Gresik 298 MW, shown in Figure 3. In this system, Paiton's bus is the swing node and others are the PV nodes. System capacity is 100,000 MVA. The Test generators are Tanjung Jati B's power plant.

\subsection{Loadflow Calculation}

The scheme definition is unbalanced condition. According to this plan, using EDSA 2000 software program based on Newton-Raphson method we can get the flow calculation results in Figure 4. Table 1 presents a three-phase volatge values of generator terminal before and after loading conditions. It is shown that voltage variatons of the generator terminal influenced by unbalanced load and the phenomenons are happent at their angle phases which are swung from their origin values.

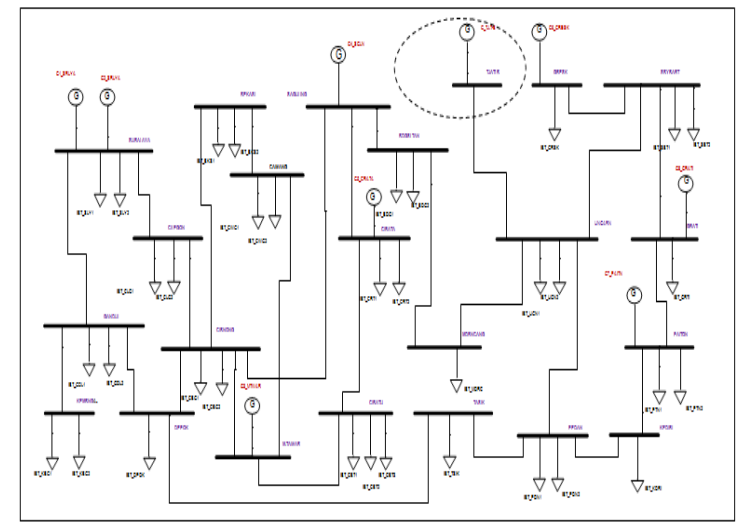

(a) Single-line diagram

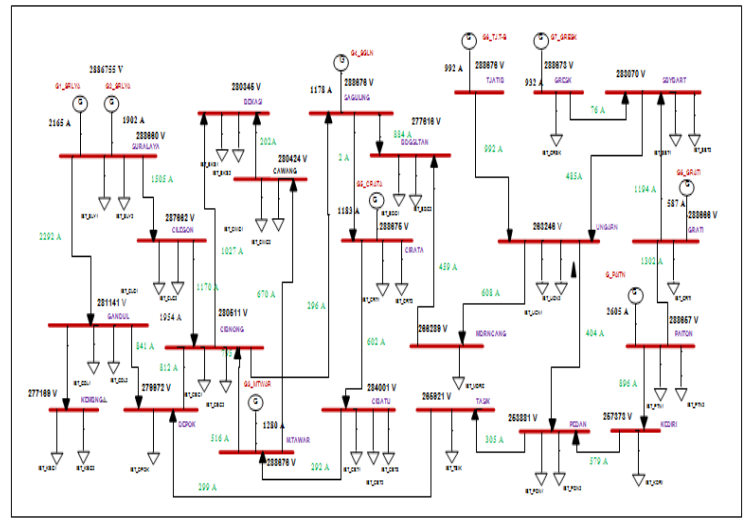

(b) Distribution of flow calculation

Figure 4. The 500 kV EHV Jamali System

Table 1. Values of Generator Terminal Voltages

\begin{tabular}{ccc}
\hline Condition & Phase & Tanjung Jati B \\
Stand-alone & $a$ & $1 \angle 0^{\circ}$ \\
& $b$ & $1 \angle 120^{\circ}$ \\
Connected grid and all of IBTs & $c$ & $1 \angle 240^{\circ}$ \\
are balanced & $a$ & $1 \angle-12^{\circ}$ \\
Connected grid and all of IBTs & $b$ & $1 \angle 120^{\circ}$ \\
are 5\% of unbalanced & $c$ & $1 \angle 240^{\circ}$ \\
Vb=0.383 V Vc=0.334 V & $a$ & $1 \angle-13.5^{\circ}$ \\
Connected grid and all of IBTs & $b$ & $1 \angle 120^{\circ}$ \\
are 7.5\% of unbalanced & $c$ & $1 \angle 240^{\circ}$ \\
$\mathrm{Va}=0.258 \mathrm{~V} \quad \mathrm{Vb}=0.408 \mathrm{~V} \quad \mathrm{Vc}=0.334 \mathrm{~V}$ & $a$ & $1 \angle-13.8^{\circ}$ \\
\hline
\end{tabular}




\subsection{Generator's Contribution Calculation}

By using the common method, the Jamali System can be divided into 13 commons, such as 6 commons of supplied energy by generator from the one bus and 7 commons of supplied energy by generator from different buses, shown in Figure 5. The detail of line-flow is shown in Table 2. Another information is generator domain shown at Table 3. Table 4 represents the information about common, rank and group of bus. Meanwhile, Table 5 represents the information about link. Figure 6 represents the state-graph diagram that describes line flow between buses.

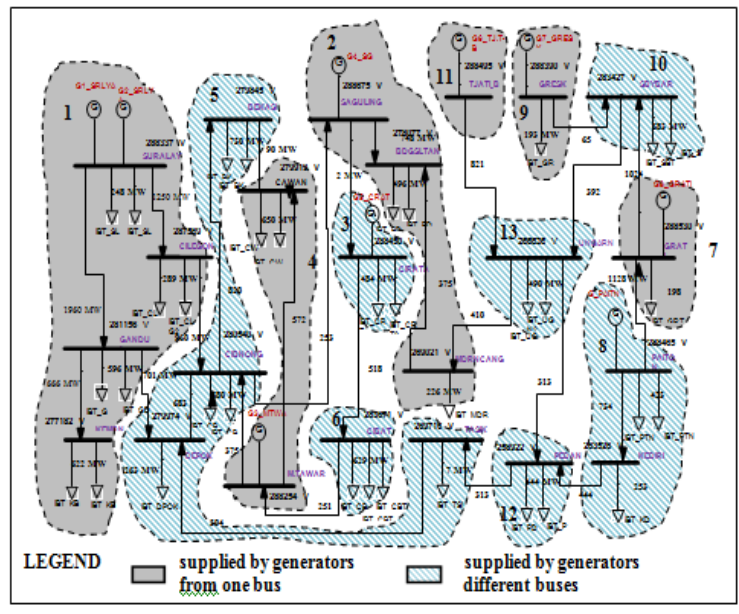

Figure 5. Flows and commons under balanced condition

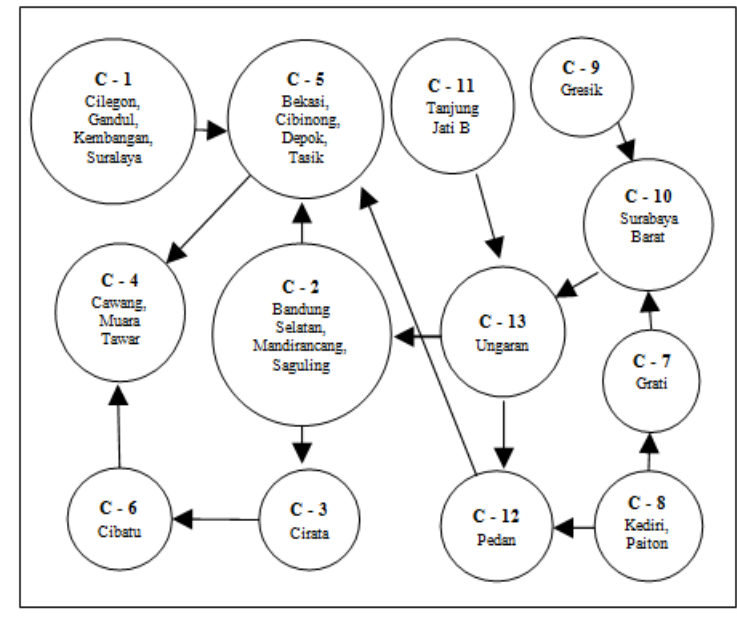

Figure 6. State-graph diagram for the balanced case

Table 2. Line Flow Detail

\begin{tabular}{llcllc}
\hline From Bus & To Bus & Flow (MW) & From Bus & To Bus & Flow (MW) \\
\hline Bandung Selatan & Mandirancang & -375 & Depok & Tasik & -304 \\
Bandung Selatan & Saguling & -748 & Gandul & Suralaya & -1960 \\
Bekasi & Cawang & 90 & Gandul & Kembangan & 666 \\
Bekasi & Cibinong & -820 & Grati & West Surabaya & 1024 \\
Cawang & Muara Tawar & -572 & Grati & Paiton & -1128 \\
Cibatu & Cirata & -516 & Gresik & West Surabaya & 65 \\
Cibatu & Muaran Tawar & 251 & Kediri & Paiton & -734 \\
Cibinong & Cilegon & -96 & Kediri & Pedan & 444 \\
Cibinong & Depok & -683 & Mandirancang & Ungaran & -410 \\
Cibinong & Muara Tawar & -375 & Pedan & Tasik & 313 \\
Cibinong & Saguling & 253 & West Surabaya & Ungaran & 392 \\
Cilegon & Suralaya & -1250 & Tanjung Jati B & Ungaran & 821 \\
Cirata & Saguling & -2 & Ungaran & Pedan & 313 \\
Depok & Gandul & -701 & & & \\
\hline
\end{tabular}

Table 3. Domain Information of the System

\begin{tabular}{cclccl}
\hline Common & Rank & \multicolumn{1}{c}{ Buses } & Common & Rank & \multicolumn{1}{c}{ Buses } \\
\hline 1 & 2 & Cilegon, Gandul, Kembangan, Suralaya & 8 & 2 & Kediri, Paiton \\
2 & 1 & West Bandung, Mandirancang, Saguling & 9 & 1 & Gresik \\
3 & 2 & Cirata & 10 & 2 & West Surabaya \\
4 & 1 & Cawang, Muara Tawar & 11 & 1 & Tanjung jati B \\
5 & 4 & Bekasi, Cibinong, Depok, Tasik & 12 & 8 & Pedan \\
6 & 3 & Cibatu & 13 & 4 & Ungaran \\
7 & 1 & Grati & & & \\
\hline
\end{tabular}

Table 4. Information of the Common, Rank, and Bus

\begin{tabular}{ll}
\hline \multicolumn{1}{c}{ Generator } & \multicolumn{1}{c}{ Buses which supplied by generator } \\
\hline Suralaya 1-2 & Bekasi, Cibinong, Cilegon, Depok, Gandul, Kembangan, Pedan, Suralaya, and Tasik \\
Cirata & Cibatu, and Cirata \\
Muara Tawar & Bekasi, Cawang, Cibatu, Cibinong, Depok, Muara Tawar, Pedan, and Tasik \\
Saguling & West Bandung, Cibatu, Cirata, Mandirancang, Pedan, Saguling, and Ungaran \\
Tanjung Jati B & Tanjung Jati B, Ungaran, and Pedan \\
Grati & Grati, Kediri, Paiton, Pedan, West Surabaya, and Ungaran \\
Gresik & Gresik, Pedan, West Surabaya, and Surabaya \\
Paiton & Kediri, Paiton, and Pedan \\
\hline
\end{tabular}


Table 5. Information of the Domain of System

\begin{tabular}{|c|c|c|c|c|c|c|c|}
\hline Link No. & From Common & To Common & Link Flow (MW) & Link No. & From Common & To Common & $\begin{array}{c}\text { Link Flow } \\
\text { (MW) }\end{array}$ \\
\hline 1 & 1 & 5 & $965+711$ & 8 & 7 & 8 & 1128 \\
\hline 2 & 2 & 3 & 2 & 9 & 7 & 10 & 1028 \\
\hline 3 & 2 & 5 & 253 & 10 & 8 & 12 & 444 \\
\hline 4 & 3 & 6 & 516 & 11 & 9 & 10 & 659 \\
\hline 5 & 4 & 5 & $170+375$ & 12 & 10 & 13 & 392 \\
\hline 6 & 4 & 6 & 251 & 13 & 11 & 13 & 821 \\
\hline 7 & 5 & 12 & 237 & 14 & 12 & 13 & -313 \\
\hline
\end{tabular}

Table 6. Contribution Factor of Tanjung Jati’s Generator

\begin{tabular}{cccc}
\hline Common No. & Percentage of contribution (\%) & Common No. & Percentage of contribution (\%) \\
\hline 1 & 0 & 8 & 0 \\
2 & 24.97 & 9 & 0 \\
3 & 0 & 10 & 0 \\
4 & 0 & 11 & 100 \\
5 & 1.81 & 12 & 28.03 \\
6 & 0 & 13 & 67.79 \\
7 & 0 & & \\
\hline
\end{tabular}

The calculation of each generator into flows and loads can be done using Equation (8). The results is shown in Table 6. According to Figure 4 and Table 6, it can be evidenced that West Bandung, and Mandirancang buses ( common no.2), Pedan bus (common no.12) and Ungaran bus (common no. 13) are buses which supplied more energy then others by Tanjung Jati B bus. Consequently, West Bandung, Mandirancang, Pedan, and Ungaran buses are influencing buses that contribute energy significantly to Tanjung Jati B’s power plant.

\subsection{Synchronous Generator Model Verification}

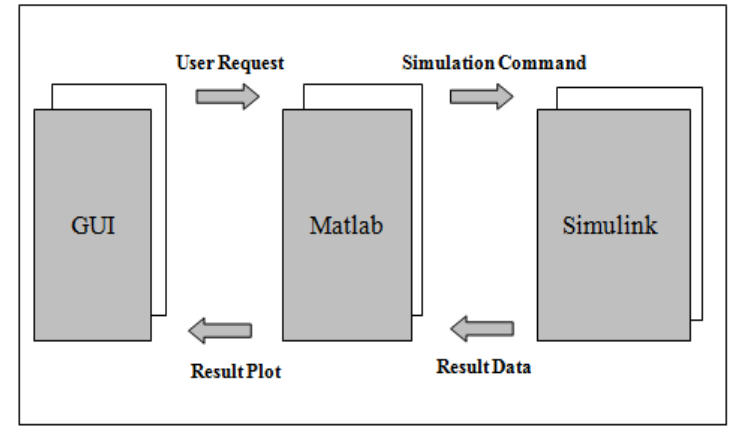

Figure 6. Designed Simulator with GUI

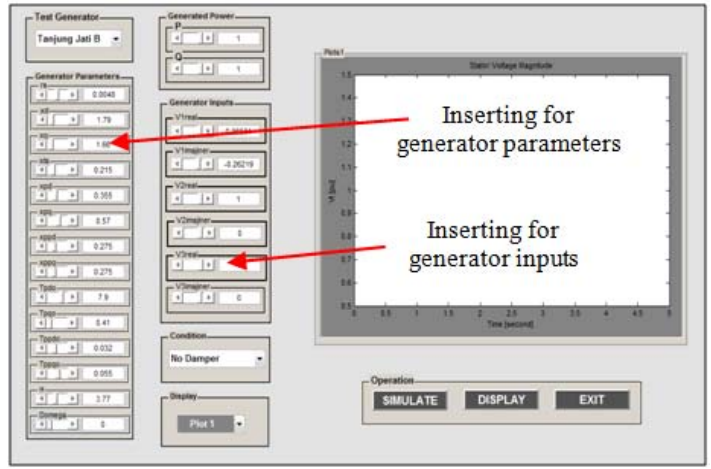

Figure 8. The window of inserting the inputs for balanced generator and unbalanced inputs

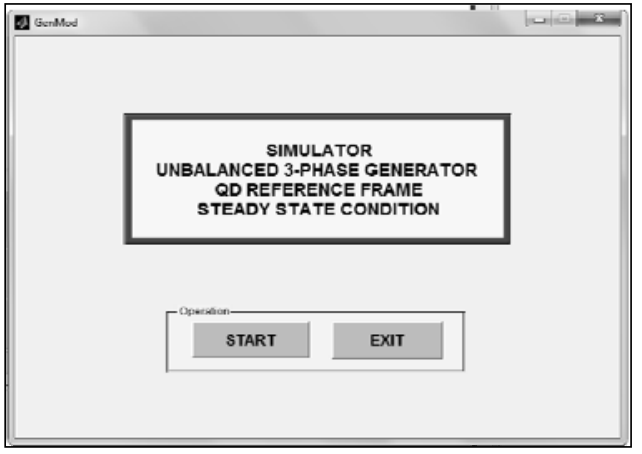

Figure 7. The main window of the developed tool

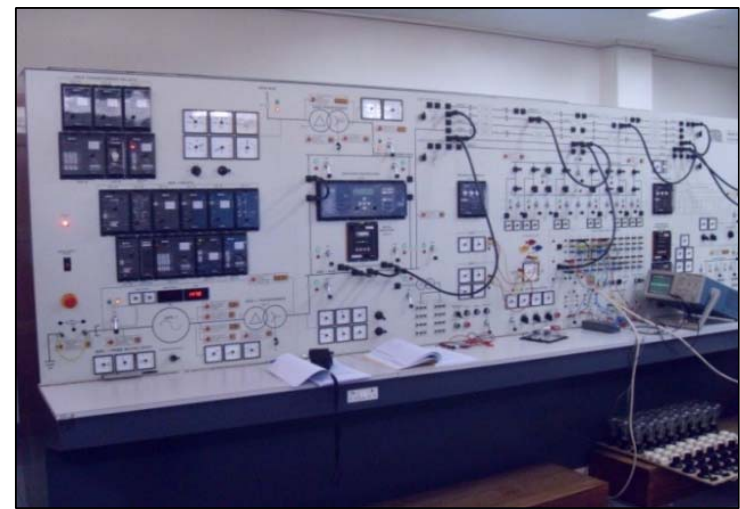

Figure 9. PSS Tecquipment NE9070 
A software package which embedded in generator virtual laboratory and applied Matlab’s GUI facilities has been created for analysis synchronous generator under unbalanced steady-state conditions (Figure 6). Matlab’s GUI is a graphical display that contains devices, or components, that enable a user to perform interactive tasks [21]. As an example of using Matlab’s GUI capabilities, menu and plotting commands are implemented in a script file to provide interactive windows. The main menu, which is displayed after running the file, shown in Figure 7 and Figure 8.

The verification of the generator model is judged through comparing between generator's respon by PSS Tecquipment NE9070, shown in Figure 9 and by the proposed simulator under no load, balanced, and unbalanced conditions, respectively.

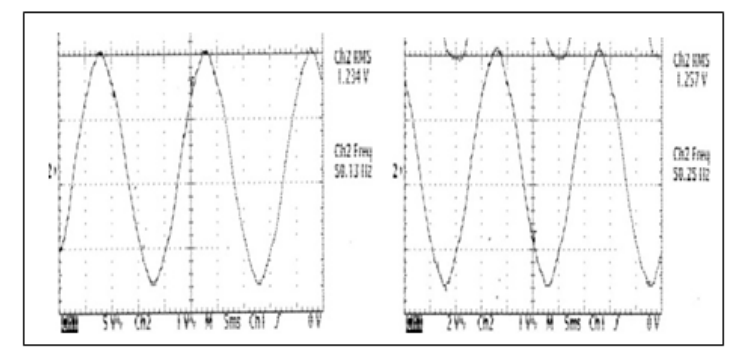

(0.72 PF exct.)
(0.81 PF exct.)

Figure 10. The output of PSS Tecquipment NE 9070

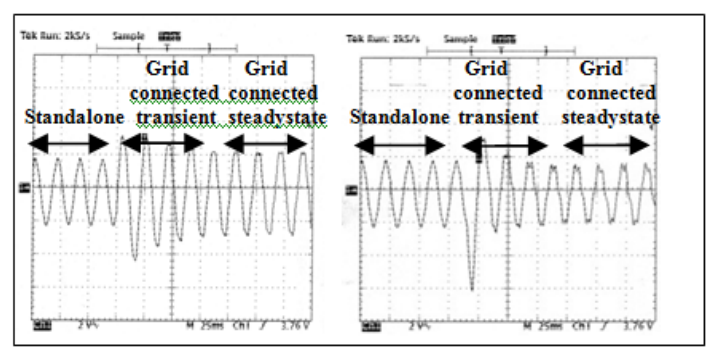

(unbalanced loads) (balanced loads)

Figure 11. Outputs of the PSS Tecquipment NE 9070

Under no load, the output respons of PSS Techquipment NE9070 are non-sinusoidal with varied excitations, eventhough the P.F value is more than 0.8, shown in Figure 10. The generator's outputs are always non-sinusoidal under standalone operation. The waveform of it will change into sinusoidal form when the generator is connected to the grids.

The results of proposed generator's model simulation considering P.F variations are described in Figure 12. It is shown that output respons are in non-sinusoidal forms although the value of P.F excitation is reached up to 0.9. Comparing both Figure 10 and Figure 12 concludes that the output respons of proposed generator model have similar trend to the output of PSS Techquipment NE9070.

Figure 11 presents the output respons of PSS Techquipmen NE9070. When synchronous generator is under unbalanced load condition, its steady state respon will oscillates less than under balanced load condition. The oscillation magnitude of unbalanced load during transient condion is bigger than balanced loads counterpart.

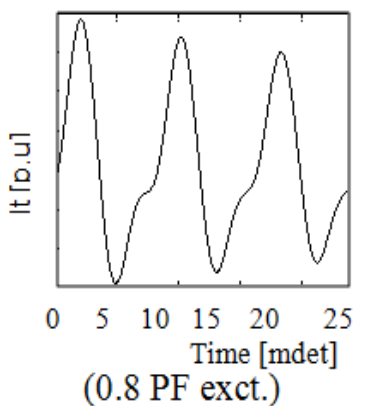

Figure 12. The output of proposed standalone gen

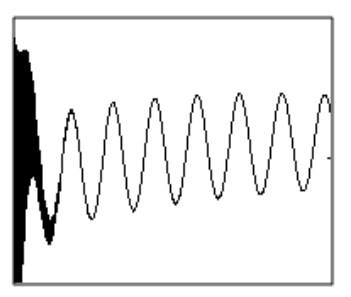

0255075100125150200 Waktu [mdet] (unbalanced loads)

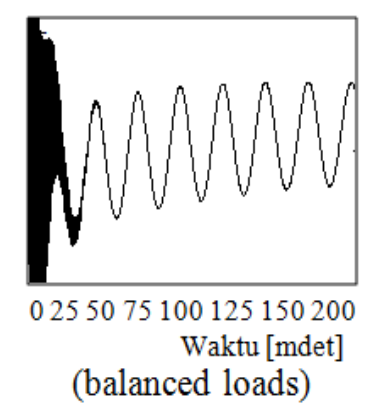

(balanced loads)

Figire 13. The outputs of the proposed connected gen

This condition is also occured during simulation of the proposed synchronous model shown in Figure 13. The oscillation of stator voltage of synchronous generator during interconnecting with $7.5 \%$ unbalanced grid is bigger than it is connected to balanced grid. Concludely, the proposed model is valid as a synchronous generator test model. 


\subsection{Dynamic Simulation of Unbalaced Steady-state Condition}

According to the Table 1, it was seen that a three-phase unbalanced load (of the grids) causes a shift in the angle of phase- $a$ of generator terminal at steady state condition. The percentage of unbalanced load is proportional to the value of phase angle shift.

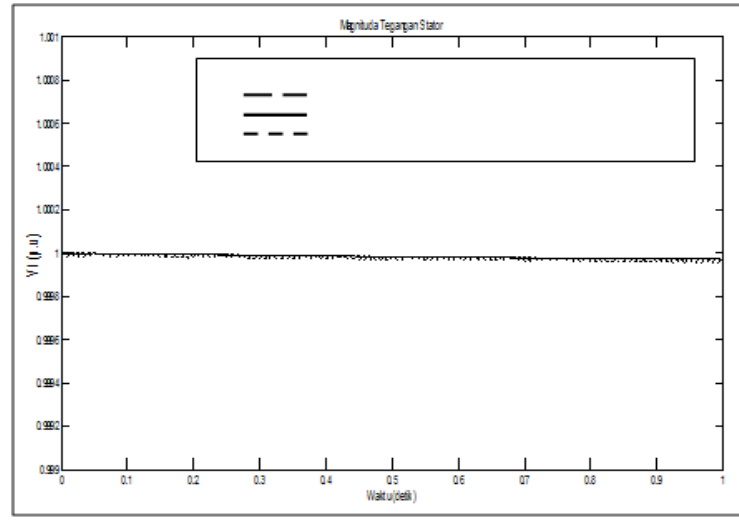

(Stator voltage magnitude)

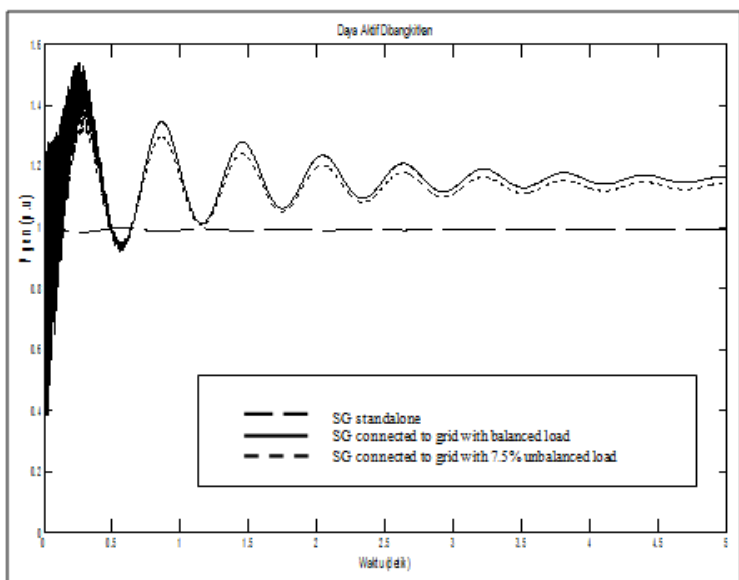

(Generated active power)

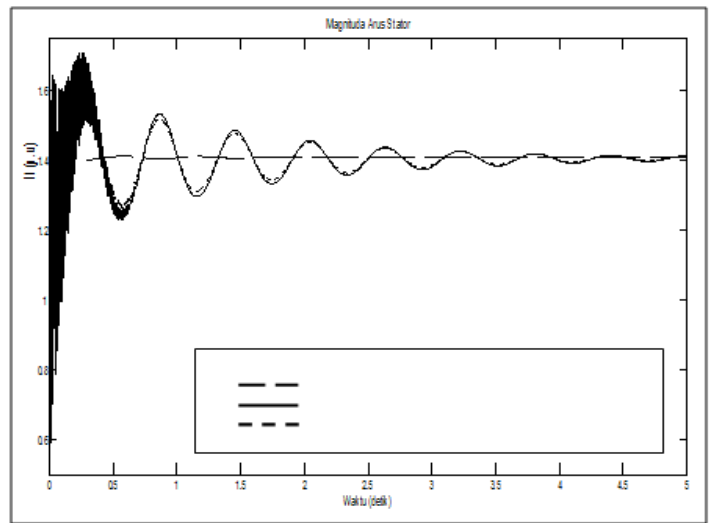

(Stator current magnitude)

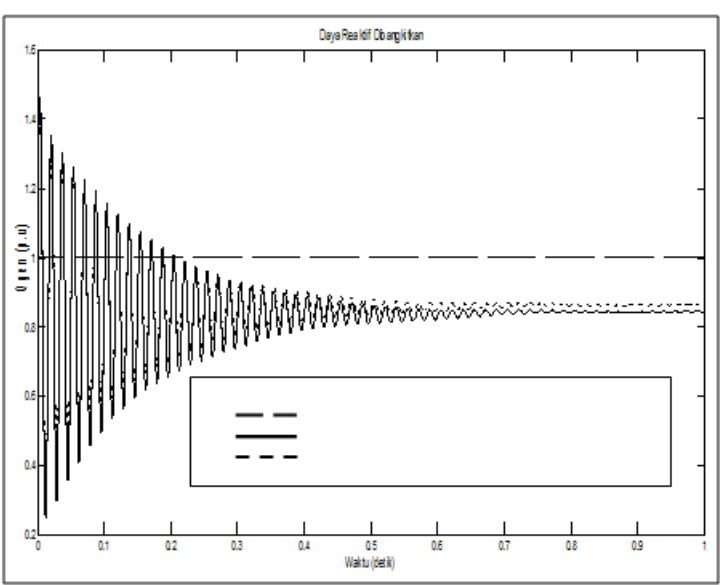

(Generated reactive power)

Figure 14. The steady-state dynamic of voltage, current, and power of synchronous generator

An increase in the percentage of unbalanced load on the entire IBTs of the grids by $5 \%$ will increase in the phase-shift angle of $1.5^{\mathrm{O}}$; a further percentage increase by $2.5 \%$ would only increase the shift of the phase angle of $0.3^{\mathrm{O}}$.

The unbalanced load does not affect to variables of generator, namely stator voltage magnitude and the rotational speed of the rotor. However, a significant influence occurs in other variables that are generator stator current, generated active power and reactive power. Generated active power has the greatest influence on the effects of $7.5 \%$ unbalance that is up to 0.52 p.u.

In the phase- $a$, the grid experienced a moment of loading, both in balance and unbalance; the zeroaxis increases from point 0 p.u to the point 0.6 p.u. In contrast, both the phase- $b$ and phase- $c$ are actually declining, from the point 0 p.u to -0.6 p.u. 


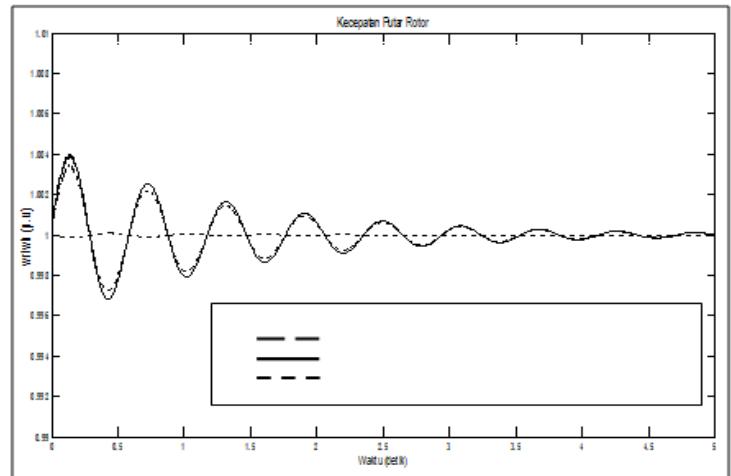

(Rotor speed)

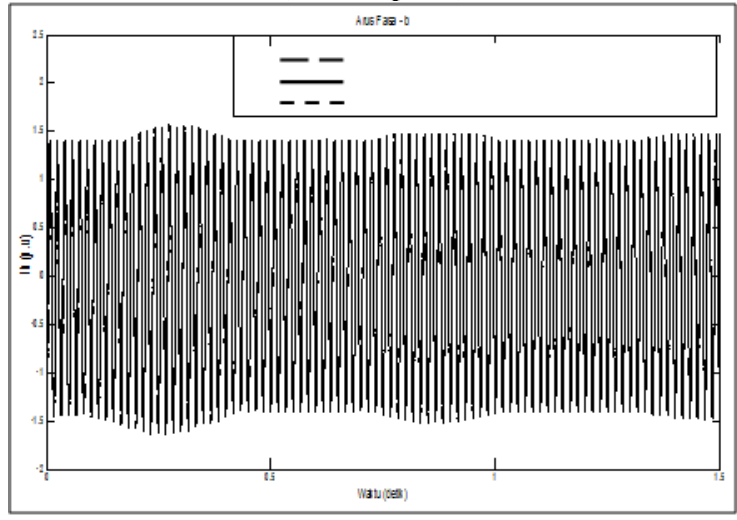

(Phase- $b$ current)

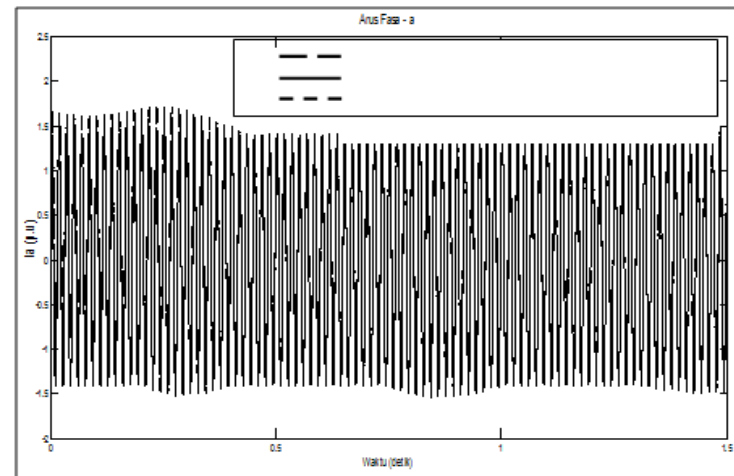

(Phase- $a$ current)

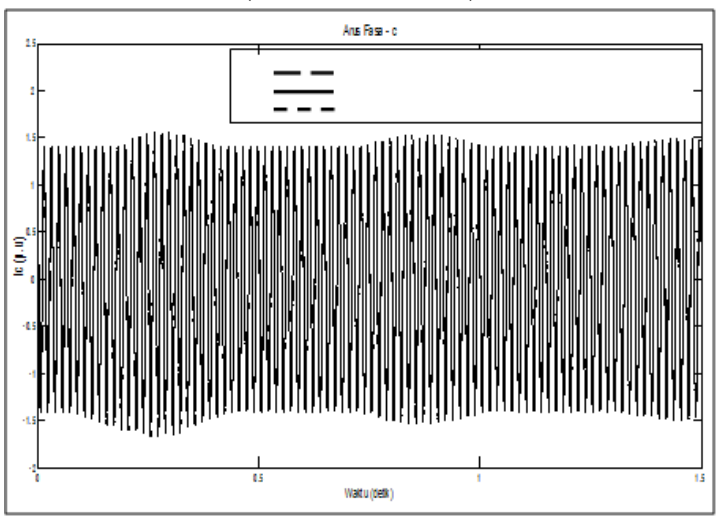

(Phase-c current)

Figure 14. The steady state dynamic of rotor speed and phase curents of synchronous generator

\section{CONCLUSION}

In this paper, a study was presented about the unbalanced loads impact on a synchronous generator connected to $500 \mathrm{kV}$ EHV Jamali. The system can be represented by a virtual generator laboratory which are the combination between both unbalanced three-phase Newton-Raphson loadflow and the rotor's qd0 reference frame of synchronous generator. To better explain the contribution of generator into loads and lines was carried out through the electricity tracing analysis.

The main conclusion that could be drawn with this study cases are that unbalanced three-phase loads cause a shift in the angle of phase- $a$ of generator terminal at steady state condition. The increasing in the percentage of unbalanced load on the entire grid by $5 \%$ will increase in the phase-shift angle of $1.5^{\mathrm{O}}$; a further percentage increase by $2.5 \%$ would only increase the shift of the phase angle of $0.3^{\mathrm{O}}$.

The significant influence of unbalanced load occurs in generated active and reactive powers, stator current magnitude, and phase currents. Meanwhile, the two variables of generator, namely stator voltage magnitude and the rotor speed are remaining constan.

\section{ACKNOWLEDGEMENTS}

The authors are thankful to the Indonesian Directorate General of Higher Education (DIKTI) for funding this project (in the form of Competitive Research Grant or Penelitian Hibah Bersaing) and to the management of Depatment of Electrical Engineering, STTNAS, Yogyakarta for providing required facilities.

\section{REFERENCES}

[1] Gustavsson I, “Laboratory Experiments in Distance Learning,” International Conference on Engineering Education, Vol. 8B, pp. 1-14, 2001.

[2] Teodorescu R, Iov F, Lungeanu F, Tataru A. M, Dumitreu T, and Panaitescu R, "The Development of A Simulink Toolbox for Advanced Electrical Drives Simulation," The 6th International Conference on Optimization of Electrical and Electronic Equipments, Vol. 2, pp. 573-576, 2008.

[3] Ruiz D, Asiain T. I, and Olguin D, “Teaching and Research Laboratory Simulator of Electric Power Systems," The $29^{\text {th }}$ Annual Frontie in Education, Vol. 1, No. 116b, pp. 8-14, 1999. 
[4] Menendez L. M, Mandado E, Salaveria A, and Dacosta J. G, "Virtual Electronics Laboratory: A new tool to improve industrial Electronics Learning," 32 ${ }^{\text {nd }}$ Annual Conference on Industrial Electronics, pp. 5445-5448, 2006.

[5] Birt K.A, Graffy J.J, and McDonald J.D, “Three-Phase load Flow Program,” IEEE Transaction on Power Apparatus System, Vol. 95, No. 1, pp. 59-66, 1976.

[6] Saha T. N, Basu T. K, "Analysis of Asymetrical Faults in Synchronous Generators by dq0 Frame of Reference," Proceeding IEE, Vol. 119, No. 5, pp. 587-595, 1972.

[7] Lupsa-Tataru L, "Comparative Simulation Study on Synchronous Generators Sudden Short Circuits,” Journal in Modelling and Simulation in Engineering. Vol. 8, pp. 1-11, 2009.

[8] Peng L, "Overloading Algorithm of Synchronous Generators Under Unbalanced Steady State Operation," International Conference on Electrical Machine and system (ICEMS), pp. 1-6, 2011.

[9] Salim R. H, Ramos R. A, and Bretas N. G. "Analysis of the Small Signal Dynamic Performance of Synchronous Generators under Unbalanced Operating Conditions,” Power and Energy Society General Meeting, pp. 1-8, 2010.

[10] Salim R. H, and Ramos R. A, "Model-Based Approach for Small-Signal Stability Assesment of Unbalanced Power System,” IEEE Transaction on Power Systems, Vol. 27, No. 4, pp. 1-8, 2010.

[11] Ramya R, and Selvi K, "Simulation of Synchronous Generator with Fuzzy based Automatic Voltage Regulator," International Journal of Electrical and Computer Engineering (IJECE). Vol. 4, No. 6, pp. 798-805, 2012.

[12] Trinadha A, Kumar A, Sandhu K. S, "Study of Wind Turbine based SEIG under Balanced/Unbalanced Loads and Excitation,” International Journal of Electrical and Computer Engineering (IJECE), Vol. 2, No. 3, pp. 353-370, 2012.

[13] Mutthy S. S, Singh B, Gupta S, and Gulati B. B. "General Steady-State Analysis of Three-Phase Self-Excited Induction Generator Feeding Three-Phase Unbalanced Load/Single-Phase Load for Stand-alone Applications," IEEE Transaction on Power, Generation, Transmission, and Distribution, Vol. 150, No, 1, pp. 49-55, 2003.

[14] Bansal B. C, “Three-Phase Self-Excited Induction: An Overview," IEEE Transaction on Energy Conversion, Vol. 20, No. 2, pp. 292-299, 2005.

[15] Acha E, Fuerte-Esquivel C, Ambriz-Pérez H, and Angeles-Camacho. "FACTS, Modelling and Simulation in Power Networks,” John Willey \& Sons, LTD., Chicester, England, 2005.

[16] EDSA Technical. 2000. Available : http://www.edsa.com

[17] Sugiarto, Hadi S. P, Tumiran, Wijaya F.D, "Teaching the Large Synchronous Generator Dynamic Model under Unbalanced Steady-State Operation,” The $5^{\text {th }}$ International Conference on Information technology and Electrical Engineering (ICITEE), pp. 425-429, 2013.

[18] Boldea I, “Synchronous Generator,” Boca Raton, FL: Taylor \& Francis Group, LLC, 2006.

[19] Krause P. C, Wasynczuk O, and Sudhoff S. D, "Analysis of Electric Machinery and Drive Systems,” WilleyInterScience, A John Willey \& Sons, Inc. Publishing, New York, 2002.

[20] Kirschen D, Allan R, and Strbac G, “Contributions of Individual Generators to Loads and Flows,” IEEE Transaction on Power Systems, Vol. 12, No. 1, pp. 52-60, 1997.

[21] Suryasen K, Devadas, K. V, Harish A, “GUI based Testing Tool for Transformer," International Journal of Electrical and Computer Engineering (IJECE), Vol. 4, No. 3. pp. 356-365, 2014.

\section{BIOGRAPHIES OF AUTHORS}

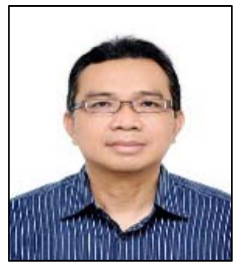

Sugiarto received the Bachelor degree, Master degree, and Doctor degree in Electrical Engineering from Gadjah Mada University, Indonesia, in 1989, 2000, and 2014, respectively. Since 1990, he is working as Senior Lecturer in the Department of Electrical Engineering, Sekolah Tinggi Teknologi Nasional, Yogyakarta, Indonesia. His research interest is model of electric machinary, control system, and artificial intelligent.

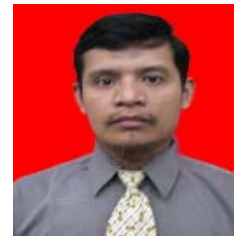

Arif Basuki received the Bachelor degree and Master degree in Electrical Engineering from Gadjah Mada University, Indonesia, in 1996 and 2002, respectively. Since 1997, he is working as Lecturer in the Department of Electrical Engineering, Sekolah Tinggi Teknologi Nasional, Yogyakarta, Indonesia. His research interest includes microcontroller and microprocessor system

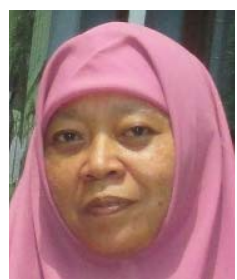

Mytha Arena received the Bachelor degree in Electrical Engineering from Gadjah Mada University, Indonesia, in 1996. She received Master degree in Electrical Engineering from Institute Technology of Sepuluh November (ITS), Surabaya, Indonesia in 2001. Since 2002, she is working as Lecturer in the Department of Electrical Engineering, Sekolah Tinggi Teknologi Nasional, Yogyakarta, Indonesia. His research interest includes analog electronic, digital system design, and telecommunication 